\title{
The role of sensory preconditioning in memory retrieval by preverbal infants
}

\author{
RACHEL BARR \\ Georgetown University, Washington, D.C. \\ and \\ HEIDI MARROTT and CAROLYN ROVEE-COLLIER \\ Rutgers University, Piscataway, New Jersey
}

\begin{abstract}
Infants' memories are highly specific to their training stimuli; they rarely transfer learned responding. In two experiments, we asked whether sensory preconditioning facilitates the transfer of deferred imitation. In Experiments 1A and 1B, 6-month-olds were simultaneously preexposed to Puppets A and $\mathrm{B}$ and then saw target actions modeled on Puppet $\mathrm{A}$. The infants associated the paired puppets and imitated the actions on Puppet B. In Experiment 2, the preexposure procedure was repeated, but the actions were modeled on Puppet A with a toy train in view. The infants also associated Puppet A and the train: Either object effectively reactivated both forgotten memories; thereafter, the infants again imitated the actions on Puppet B. These findings reveal that infants form specific and enduring associations between stimuli they have merely seen together. These associations facilitate the transfer of deferred imitation, both directly and indirectly, through connections to other associations.
\end{abstract}

Human infants spend the better part of their first halfyear merely looking at the world around them. Not only does this extended period of visual inspection have important implications for how infants perceive the physical world, but also it seems likely that they learn many of the relationships in their visual surround during this time. They cannot show what they have learned, however, unless they are given an opportunity to do so. Using an operant auditory discrimination procedure, for example, DeCasper and Spence (1986) found that newborn humans sucked harder to listen to their mother read a Dr. Seuss passage that she had repeatedly read aloud when they were in utero than to listen to her read a novel Dr. Seuss passage. This example also illustrates the specificity of infants' early learning - a specificity that severely constrains their ability to generalize beyond the original input.

The specificity of early learning continues to be pronounced throughout the first half-year of life (Hartshorn et al., 1998). For example, learning occurring between 2 and 6 months of age has been studied extensively using an operant conditioning task in which infants learn to move an overhead crib mobile by kicking. When tested later with either the original stimulus or one that differs

This research was supported by Grants MH32307 and MH00902 from the National Institute of Mental Health to the third author. We thank Jennifer Campanella, Paul Muentener, and Aurora Vieira for assisting with the data collection for Experiments 1B and 2. Address correspondence to C. Rovee-Collier, Department of Psychology, Busch Campus, Rutgers University, 152 Frelinghuysen Rd., Piscataway, NJ 08854-8020 (e-mail: rovee@ rci.rutgers.edu). in some way, they cannot recognize it even 1 day later if more than a single object on the original five-object mobile is different; however, their recognition of the original mobile is excellent after the same delay (Hayne, Greco, Earley, Griesler, \& Rovee-Collier, 1986).

In studies of deferred imitation with infants between 6 and 12 months of age, infants' learning is similarly specific to the particular objects on which the target actions were originally modeled. In such tasks, infants must reproduce the modeled actions after a delay. Hayne, Boniface, and Barr (2000), for example, modeled a series of target actions on either a pink rabbit or a gray mouse hand puppet for 6- and 12-month-old infants. At both ages, deferred imitation was excellent 1 day later when the infants were tested with the original puppet, but it was severely disrupted by switching the puppets between modeling and testing (e.g., from the rabbit to the mouse and from the mouse to the rabbit).

Chen, Lariviere, Heyser, Spear, and Spear (1991) proposed that sensory preconditioning (SPC) might be particularly advantageous for young organisms that are otherwise unlikely to generalize to novel stimuli. The basic SPC paradigm involves three phases: (1) Two stimuli (S1, S2) are repeatedly paired; (2) a distinctive response is trained to one of the stimuli (S1); and (3) the subject is tested with other stimulus (S2). If the subject performs the learned response to $\mathrm{S} 2$, this is taken as evidence that an association was formed between $\mathrm{S} 1$ and $\mathrm{S} 2$ during the preexposure phase and that the association facilitated the subsequent transfer of the learned response from $\mathrm{S} 1$ to S2. Because the organism makes no overt response when the association is originally formed, SPC is often re- 
ferred to as behaviorally silent learning (Brogden, 1939; Coppock, 1958; Seidel, 1959). Chen et al. (1991) found that when rat pups as young as $3 \mathrm{~h}$ were simultaneously preexposed to two odors that they could perceptually discriminate, SPC occurred rapidly. Furthermore, it occurred more rapidly for infants than for adult rats (Cheslock, High, Varlinskaya, \& Spear, 2000).

In the classic demonstration of SPC, Brogden (1939) exposed dogs to 200 simultaneous pairings of a buzzer and a light. Then, using a fear-conditioning of procedure, he presented a shock with the buzzer to half the dogs and a shock with the light to the other half. Later, he tested the dogs with the second stimulus (light or buzzer, respectively) in the absence of the shock. The dogs exhibited conditioned fear to the second stimulus even though it had never been directly paired with the shock. A control group that was preexposed to the two stimuli separately, so that there was no opportunity to form an association between them, showed no fear to the second stimulus during the test. Researchers have since confirmed that neither unpaired exposure to S1 and S2 (Coppock, 1958; Seidel, 1959) nor differential familiarity with the test stimulus (Silver \& Meyer, 1954) is responsible for the SPC effect.

Although SPC has been studied in many mammalian species with classical and instrumental conditioning procedures (for a review, see Thompson, 1972), it has not been studied with other learning procedures, and only one report with human infants has appeared (Boller, 1997). In the present study, therefore, we attempted to extend SPC to observational learning by human infants. To this end, we used a deferred imitation paradigm with 6-month-olds. We asked whether young infants would learn the relationship between objects that they merely see together in their visual surround and whether doing so would enable them to imitate actions on one of these objects after having seen the actions modeled on the other. In addition, we asked how stable this association might be. Could the association, for example, be reactivated after a period sufficiently long to induce forgetting?

\section{EXPERIMENT 1A Sensory Preconditioning and Deferred Imitation}

In the first study of SPC with human infants, Boller (1997) simultaneously preexposed 6-month-olds to two cloth liners (contexts) hanging side by side for $1 \mathrm{~h}$ daily for 7 days. She preexposed an unpaired control group to the same contexts for $30 \mathrm{~min}$ each at different times of day for 7 days. One day after their last exposure, she trained the infants in both groups to move a crib mobile by kicking for 2 days in one of the contexts and tested them 1 day later in the other context. Usually, 6-montholds who are tested 1 day after training in a context that differs from the training context exhibit no retention (Borovsky \& Rovee-Collier, 1990; Hartshorn et al., 1998). She found that only the infants who had been simultaneously preexposed to the two contexts kicked sig- nificantly above baseline in the second context, suggesting that the infants had formed an association between the two contexts when they were preexposed together. The infants in the unpaired control group did not kick above baseline in the second context, even though it was equally familiar, supporting the inference that the pairedpreexposure group had formed an association between the two contexts during the initial phase. Thus, despite having received no specific reinforcement for doing so, 6-month-old infants learned the visual characteristics of the two contexts that they saw together and formed an association between them.

In Experiment 1A, we asked whether 6-month-old infants would similarly form an association between two puppets (a black-and-white cow and a bright yellow duck with an orange bill) that were preexposed in their own home and, after actions were later modeled on one of the puppets, whether they would imitate the actions on the other one. Because simultaneous presentation is known to facilitate transfer, we simultaneously preexposed infants to Puppets A and B, using the same exposure parameters as Boller (1997). We hypothesized that if the infants associated the two puppets during the preexposure phase, the infants tested with Puppet B (Group Paired/B) should imitate the target actions that had been modeled on Puppet A.

To ensure that the puppets were perceptually discriminable and that the infants did not ordinarily generalize from one to the other, the infants in Group $x / B$ saw the target actions modeled on Puppet A and were tested with Puppet B but were not preexposed to either puppet. We predicted that if the puppets were perceptually distinct, the infants in this group would not generalize the modeled actions from Puppet A to Puppet B during the test. As additional control measures, we preexposed infants to Puppets A and B in an unpaired fashion and tested them with Puppet B (Group Unpaired/B). We predicted that these infants would not form an association between the two puppets and, therefore, would not imitate the modeled actions on Puppet B (see also Brogden, 1947; Seidel, 1959).

\section{Method}

Subjects. The subjects were 24 full-term, healthy infants (13 girls, 11 boys) who were recruited from public birth announcements and by word of mouth. Infants' mean age on the 1st day of the experiment was 191.8 days $(S D=7.3)$. They were Asian $(n=3)$, Latino $(n=1)$, and Caucasian $(n=20)$. Their parents' mean educational attainment was 15.7 years $(S D=0.9$; not reported, $8.3 \%)$, and their mean rank of socioeconomic status (Nakao \& Treas, 1992) was $66.7(S D=18.4$; not reported, $16.7 \%)$. Four additional infants were not included in the final sample for either refusing to touch the puppet or sibling interference.

Apparatus. Two hand puppets (a black and white cow and a yellow duck) were specially constructed for these experiments (see Figure 1). Both were $30 \mathrm{~cm}$ in height and made of soft acrylic fur. A felt mitten $(8 \times 9 \mathrm{~cm})$ covered the right hand of each puppet. The mitten was yellow or black and exactly matched the color of the duck or the cow, respectively. A large jingle bell was secured inside the mitten during modeling of the target actions. Puppets A and B 


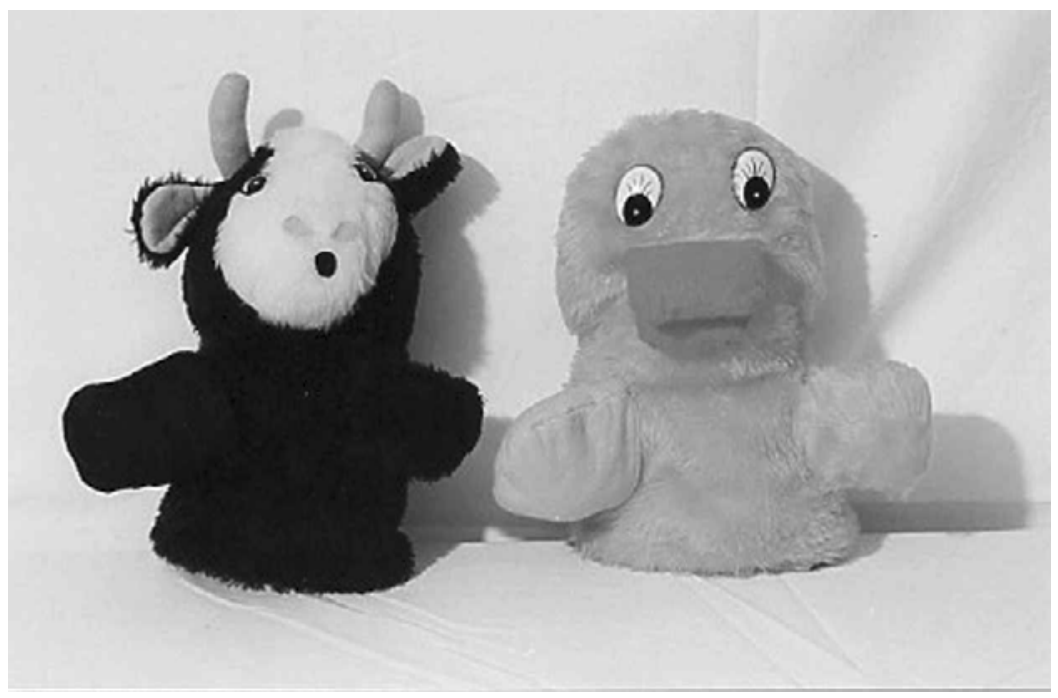

Figure 1. The two hand puppets used in Experiments 1A, 1B, and 2: a black and white cow (left) and a yellow duck (right). Designation of the cow and the duck as $A$ and $B$, respectively, was counterbalanced.

were counterbalanced during modeling and testing. A Panasonic VHS-C camcorder on a tripod was placed at right angles to the infant, and the infants' interactions with the puppet were videotaped during both the demonstration and the test sessions.

Procedure. The procedure followed in the present experiment was identical to that used in past research on deferred imitation using the puppet task with 6-month-old infants (Barr, Dowden, \& Hayne, 1996; Barr, Vieira, \& Rovee-Collier, 2001, 2002). All the infants were studied in their own homes at a time of day when they were likely to be playful. This time varied from infant to infant but remained fairly constant across all sessions for a given infant.

As they became available for study, the infants were randomly assigned to one of four groups $(n=6)$ : Group Paired/B, Group Unpaired/B, Group $\mathrm{x} / \mathrm{B}$, and the naive control group (see Table 1). The SPC group (Group Paired/B) was simultaneously preexposed to Puppets A and B. The unpaired control group (Group Unpaired/B) was also preexposed to the two puppets for a total of $1 \mathrm{~h}$ per day, but each puppet was presented alone. The preexposure control group (Group $\mathrm{x} / \mathrm{B}$ ) was not preexposed to any puppet. All of these groups saw an adult model the target actions on Puppet $A$ and were tested with Puppet B 1 day later. Finally, a naive control group saw neither a demonstration of the target actions nor either of the puppets before being tested with Puppet B. Its "imitation" score defined the baseline for the spontaneous (unlearned) production of the target behaviors by 6-month-olds. The test performance of each group was compared with the test performance of the naive control group. A group was considered to exhibit deferred imitation only if its mean imitation test score significantly exceeded the mean imitation test score of the naive control group (i.e., baseline).

Preexposure phase. During the preexposure phase, Group Paired/B was simultaneously exposed to the cow and the duck puppets (Puppets A and B) for a total of $1 \mathrm{~h}$ each day for 7 consecutive days. The puppets were displayed side by side on wooden hat stands in the infant's full view. In a diary, the parents recorded the locations where the puppets were exposed, the times of day when they were exposed, and what the infant was doing during the exposure. Group Unpaired/B was exposed to Puppets A and B separately at different times of day for a total of $1 \mathrm{~h}$ (30 min each) per day for 7 days. The parents placed the hat stand holding one of the puppets in their infant's full view for a total of $30 \mathrm{~min}$ at one time of day (e.g., in the morning), and they placed the hat stand holding the other puppet in their infant's full view for a total of $30 \mathrm{~min}$ at another time of day (e.g., in the afternoon). These parents also recorded in a diary the time, place, and actions of the infant while a given puppet was in view. If the parents failed to complete the diary, their infant was not included in the final sample. (The parents of the infants in Group $\mathrm{x} / \mathrm{B}$ and the naive control group did not participate in this phase.)

Demonstration session. For the two preexposure groups (Group Paired/B and Group Unpaired/B), the target actions were modeled on Puppet A on Day 8, 1 day after the final preexposure session. For Group $\mathrm{x} / \mathrm{B}$, the demonstration session was the 1 st day of the experiment. Before the demonstration, the experimenter interacted with each infant for $5 \mathrm{~min}$ or until she elicited a smile.

During the demonstration session, which was videotaped, the infant sat on the caregiver's knees. The experimenter knelt in front of the infant, placed Puppet A over her right hand, and positioned the puppet at the infant's eye level and approximately $80 \mathrm{~cm}$ from the infant's chest. The experimenter then removed the mitten from the puppet's right hand, shook it three times to ring the bell inside, and replaced it on the puppet's right hand. This sequence was repeated five more times for a total demonstration duration of approximately $60 \mathrm{sec}$. Immediately after the demonstration, the infants were allowed three opportunities to reproduce the target actions on Puppet A (the immediate imitation phase). The duration of this phase $(M=$ $256 \mathrm{sec}, S E=23$ ) did not differ as a function of group assignment.

Test session. The test session, which was also videotaped, occurred 1 day $( \pm 2 \mathrm{~h})$ after the demonstration for the infants in all

Table 1

Preexposure Puppets, Demonstration Puppet, Test Puppet, and Regimen (Day) as a Function of Group Assignment (Experiment 1A)

\begin{tabular}{lccc}
\hline \multicolumn{1}{c}{ Group } & $\begin{array}{c}\text { Preexposure } \\
(\text { Days 1-7) }\end{array}$ & $\begin{array}{c}\text { Demonstration } \\
\text { (Day 8) }\end{array}$ & $\begin{array}{c}\text { Test Puppet } \\
\text { (Day 9) }\end{array}$ \\
\hline Paired/B & A+B & A & B \\
Unpaired/B & A/B & A & B \\
x/B & none & A & B \\
Naive control & none & none & B \\
\hline
\end{tabular}

Note- $\mathrm{A}$ and $\mathrm{B}$ refer to different puppets. 
groups except the naive control group, whose test session was on the 1 st and only day of the experiment. During the test, the infant was again seated on the caregiver's knees, and the puppet was placed over the experimenter's right hand, as before, and within the infant's reach, approximately $30 \mathrm{~cm}$ in front of the infant. The infant was allowed $120 \mathrm{sec}$ from the time he or she first touched the puppet in which to imitate the previously modeled actions.

\section{Results and Discussion}

An imitation score was calculated for each infant by summing the number of target behaviors (remove the mitten, shake the mitten, attempt to put the mitten back on the puppet) that were produced during the test (range, 0-3). (Six-month-olds rarely attempt to replace the mitten.) One observer scored all the videotaped test sessions, while a second observer, who was blind to the infants' group assignments, independently scored $79 \%$ of the videotapes. The interobserver reliability was $98.2 \%$ $(\mathrm{kappa}=.93)$. When the two raters differed, the primary rater's score was assigned. In Experiment 1A, the raters disagreed on one occasion regarding the presence or absence of one of the three behaviors.

A one-way analysis of variance (ANOVA) over the mean immediate imitation test scores of the three groups that saw the target actions modeled indicated that they did not differ $[F(2,15)<1]$. All the infants imitated immediately, and all means equaled 1.5. This result eliminated differences in original learning as a potential basis for group differences in deferred imitation on a different test puppet. In contrast, an ANOVA over the mean deferred imitation test scores of all four groups indicated that they differed significantly $[F(3,20)=7.17, p<.01$; see Figure 2]. A post hoc test (Duncan's multiple range test, $p<.05)$ revealed that the mean deferred imitation test score of the experimental group, Group Paired/B, was significantly higher than the mean deferred imitation test scores of the three control groups, which did not differ from one another. The fact that Group Paired/B differed significantly from Group Unpaired/B, which did not perform significantly above baseline, indicated that the simultaneous pairing of Puppets A and B during the preexposure phase was essential for transfer of imitation. Furthermore, the fact that the infants who were familiarized with the test stimulus during the preexposure phase (Group Unpaired/B) failed to imitate the target actions on it ruled out sheer novelty as the basis of the imitation failure by Group $\mathrm{x} / \mathrm{B}$. The latter result is consistent with the earlier finding that mere familiarity with a test stimulus is not a factor in the SPC effect (Silver \& Meyer, 1954).

The poor deferred imitation performance of Group $\mathrm{x} / \mathrm{B}$, which was tested with a puppet different from the puppet on which the target actions were originally demonstrated (see Table 1), replicated a previous finding with 6-montholds (Hayne et al., 2000). In that study, infants tested with a novel puppet also did not imitate the target actions. These findings reveal that young infants' memories are highly specific to the stimuli that were present during encoding and are consistent with the encoding specificity principle, which states that a memory will be retrieved only if an individual encounters a cue with attributes that match those represented in the memory at the time of original encoding (Tulving \& Thomson, 1973).

In summary, when the infants were simultaneously preexposed to the two puppets (Puppets A and B) in

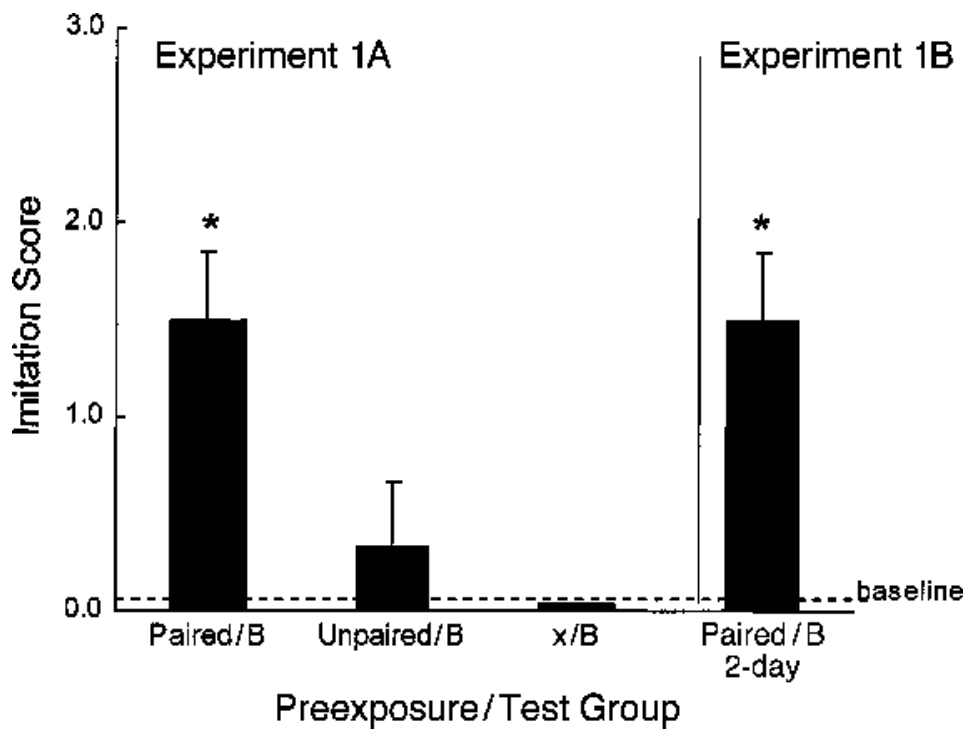

Figure 2. The mean deferred imitation test scores $(+1 S E)$ of 6-month-olds. Left panel: Groups Paired/B, Unpaired/B, and x/B (Experiment 1A). Right panel: Group Paired/B 2-Day (Experiment 1B). The dotted line indicates the baseline performance of the target actions by the naive control group. An asterisk indicates that a group scored significantly higher than the naive control group. 
Phase 1 of the SPC procedure, they apparently formed an association between them. In Phase 3, this association mediated the transfer to Puppet B of what the infants had learned when they saw the target actions modeled on Puppet A in Phase 2.

\section{EXPERIMENT 1B Attention During the Paired Preexposure}

One problem in Experiment $1 \mathrm{~A}$ was deciding how long to preexpose each of the unpaired puppets. Because we had simultaneously preexposed Puppets A and B for a total of $1 \mathrm{~h}$ per day for 7 days for the paired/B experimental group, we had elected to maintain a constant total preexposure time to the two puppets and, thus, had preexposed each puppet alone for half as long, or for $30 \mathrm{~min}$ each per day for 7 days, for the unpaired/B control group. Also in Experiment 1 A, the parents' diary entries indicated that the times, locations, and number of presentations of the paired puppets were highly variable from day to day both across infants and for a given infant. Half of the parents displayed the paired puppets for $1 \mathrm{~h}$ on a single occasion per day, for example, whereas the remaining half displayed them on multiple occasions per day. The parents also displayed the paired puppets in multiple locations that differed from the place where the target actions were subsequently demonstrated, and the infants engaged in different behaviors while the puppets were on display. Although these conditions mimicked naturalistic observational conditions, we thought it prudent to standardize Phase 1 in Experiment 1B by preexposing the paired puppets under the same conditions, at the same time, and in the same place where the target actions would be demonstrated and tested. In Experiment 1B, we also reduced the infants' total preexposure time to the paired puppets to $2 \mathrm{~h}$. This preexposure time was more than $40 \%$ shorter than the total amount of time for which the unpaired group had been preexposed to a single puppet in Experiment $1 \mathrm{~A}(2$ vs. $3.5 \mathrm{~h})$ and was more than $70 \%$ shorter than the total amount of time for which the paired group had been exposed to both puppets in Experiment $1 \mathrm{~A}$ ( 2 vs. $7 \mathrm{~h})$.

Our research questions in Experiment 1B were twofold. First, we asked how long 6-month-old infants actually look at the paired puppets during an hour. Second, we asked whether a shorter preexposure phase would support SPC and the subsequent transfer of learned responding. To answer these questions, we simultaneously exposed 6-month-olds to Puppets A and B during a single 1-h period on each of 2 successive days and measured their attention (i.e., looking behavior) to the paired puppets. One day later, we demonstrated the target behaviors on one puppet, and 1 day after the demonstration, we gave the infants a deferred imitation test with the other puppet. In all, the experimental period lasted 4 days.

\section{Method}

Subjects. The subjects were six full-term and healthy infants (2 girls, 4 boys) that were recruited as before. Their mean age on the
1 st day of the study was 186.6 days $(S D=7.0)$. The subjects were Latino $(n=1)$, Asian $(n=1)$, and Caucasian $(n=4)$. Their parents' mean educational attainment was 16.0 years $(S D=0.0)$, and their mean rank of socioeconomic status (Nakao \& Treas, 1992) was $77.3(S D=15.8)$. Four additional infants were not included in the final sample for refusing to touch the puppet $(n=2)$, experimenter error, and illness. The infants were assigned to Group Paired/B 2-Day as they became available for testing. ${ }^{1}$

Apparatus and Procedure. The cow and the duck again served as Puppets A and B; their designation was counterbalanced. The infants were simultaneously preexposed to Puppets A and B for $1 \mathrm{~h}$ per day on 2 consecutive days in the same manner as in Experiment $1 \mathrm{~A}$. This time, however, the preexposure occurred during a free-play period in which the parents provided their infants with toys. In addition, the parents were instructed to interact with their infants should the infants become fussy. One day after the preexposure phase, an adult modeled the target actions on Puppet A and the infants participated in an immediate imitation test, and 1 day after the modeling, the infants received a deferred imitation test with Puppet B. The demonstration and both test phases were also procedurally identical to those in Experiment $1 \mathrm{~A}$. The mean duration of the immediate imitation test phase was $320 \mathrm{sec}(S E=81)$.

A Panasonic VHS-C camcorder on a tripod was placed centrally behind the puppets, and the infants' looking behavior toward the puppets was videotaped during both preexposure sessions. Although all the preexposure sessions lasted $1 \mathrm{~h}(3,600 \mathrm{sec})$ per day, the actual videotaping period was always somewhat less (see Table 2). During the ensuing demonstration and test sessions, the tripod was placed at right angles to the infant, and the infant's interactions with the puppet were videotaped, as before.

\section{Results and Discussion}

Preexposure phase. A trained observer independently coded the total number of fixations and the total looking time (in seconds) in each 5-min block of all preexposure sessions, and a second observer independently coded $33 \%$ of the randomly selected videotapes. The interobserver reliability (Pearson product-moment correlations) was high for both measures (looking time, $r=$ .90; number of fixations, $r=.89$ ). As is shown in Figure 3 , both looking time (left panel) and the number of fixations (right panel) toward Puppets A and B declined steadily during each session. Both response functions resemble typical infant visual habituation data (e.g., Cohen, 1976). A repeated measures ANOVA confirmed that looking time declined significantly over successive blocks $[F(11,115)=11.91, p<.001]$, but neither the main effect of session $[F(1,115)<1]$ nor the session $\times$ block interaction $[F(1,115)=1.78$, n.s. $]$ was significant. An identical analysis confirmed that the number of fixations also declined significantly over successive blocks $[F(11,115)=$ $15.00, p<.001]$. Although the number of fixations declined significantly over sessions $[F(1,115)=4.27, p<$ $.05]$, the session $\times$ block interaction again was not significant $[F(11,115)=1.50$, n.s. $]$.

Surprisingly, the infants spent only approximately $8 \%$ of each session looking at the puppets, and their mean duration of fixation was also surprisingly short $(M=$ $3.29 \mathrm{sec}, S D=1.65$ ). That is, the infants glanced repeatedly, but only briefly, at the puppets. Thompson (1972) had argued that SPC resembles orienting behavior and had hypothesized that the degree of orienting toward a stimulus during the preexposure phase would be related 
Table 2

Cumulative Looking Time (in Seconds) Over 2 Days, Total Session Time (in Seconds) Over 2 Days, Total Percentage of Two Sessions Spent Looking at Puppets A+B, Total Number of Fixations Over 2 Days, Immediate Imitation Score, and Deferred Imitation Test Score (Experiment 1B)

\begin{tabular}{ccccccc}
\hline $\begin{array}{c}\text { Infant } \\
\text { Number }\end{array}$ & $\begin{array}{c}\text { Cumulative } \\
\text { Looking } \\
\text { Time }\end{array}$ & $\begin{array}{c}\text { Total } \\
\text { Session } \\
\text { Time }\end{array}$ & $\begin{array}{c}\text { Total } \\
\text { Percent } \\
\text { Looking }\end{array}$ & $\begin{array}{c}\text { Total } \\
\text { Number of } \\
\text { Fixations }\end{array}$ & $\begin{array}{c}\text { Immediate } \\
\text { Imitation } \\
\text { Score }\end{array}$ & $\begin{array}{c}\text { Deferred } \\
\text { Imitation } \\
\text { Test Score }\end{array}$ \\
\hline 1 & 674 & 5,364 & 12.56 & 208 & 1 & 1 \\
2 & 564 & 5,682 & 9.96 & 180 & 2 & 1 \\
3 & 451 & 6,074 & 7.59 & 180 & 2 & 2 \\
4 & 431 & 3,913 & 11.01 & 112 & 2 & 2 \\
5 & 150 & 4,811 & 5.51 & 272 & 2 & 2 \\
6 & 265 & 4,860 & 3.09 & 138 & 1 & 1 \\
Mean & 422.50 & 5,117 & 8.25 & 181.66 & 1.66 & 1.5 \\
$S D$ & 191.42 & 762 & 3.57 & 55.89 & 0.51 & 0.55 \\
\hline
\end{tabular}

to subsequent test performance. Unfortunately, both the range of the deferred imitation test scores and the sample size in Experiment 1B were too small to permit a correlational analysis. Superficially, however, Thompson's hypothesis did not appear to be supported by the individual data. Table 2 shows that the total attention of individual infants over the two sessions ranged from $3 \%$ to $12 \%$ and from 2.5 to $11.2 \mathrm{~min}$, whereas the deferred imitation scores ranged from 1 to 2 . As can be seen, the infant who spent the least amount of time $(2.5 \mathrm{~min})$ attending to the paired puppets obtained the highest deferred imitation test score (2), whereas the infant who spent the greatest amount of time (11.2 min) attending to the paired puppets obtained the lowest deferred imitation test score (1).

Imitation test phases. Imitation scores were calculated as before. Two trained observers, one being blind to the infants' group assignment, scored $100 \%$ of the videotapes for the immediate and the deferred imitation tests. Their interobserver reliability was 92\% (kappa $=$
.83). When the two raters differed, the primary rater's score was assigned. In Experiment $1 \mathrm{~B}$, the raters disagreed on three occasions regarding the presence or absence of one of the three behaviors.

A cross-experiment Student's $t$ test between the mean immediate imitation test scores of Group Paired/B from Experiment 1A and Group Paired/B 2-Day from Experiment $1 \mathrm{~B}$ indicated that their immediate imitation test performance did not differ $[t(10)<1]$. This result eliminated the possibility that different preexposure times to the paired and the unpaired puppets had produced group differences in initial learning in the prior experiment. Two cross-experiment planned comparisons were also conducted to assess whether the mean deferred imitation test score of Group Paired/B 2-Day in Experiment 1B exceeded the mean deferred imitation test scores of Group Unpaired/B and the naive control group in Experiment $1 \mathrm{~A}$. A Student's $t$ test revealed that the mean deferred imitation test score of Group Paired/B 2-Day was significantly higher than the mean deferred imita-

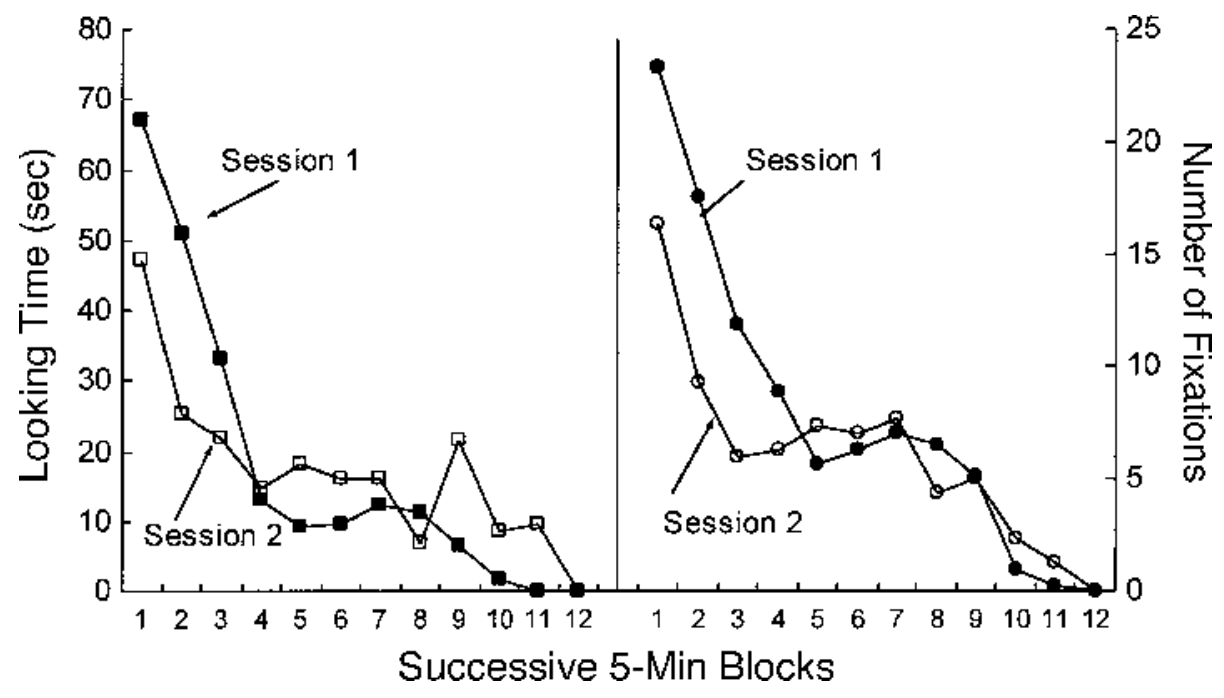

Figure 3. Left panel: The mean looking time (in seconds) of Group Paired/B 2-Day over successive 5-min blocks of each preexposure session. Right panel: The mean number of fixations of Group Paired/B 2-Day over successive 5-min blocks of each preexposure session. 
tion test score of Group Unpaired/B $[t(10)=2.90, p<$ $.02]$, even though the infants in Group Unpaired/B had been preexposed to Puppets A and B for a longer time. An identical $t$ test between the mean deferred imitation scores of Group Paired/B 2-Day and the naive control group yielded the same result $[t(10)=6.90, p<.01]$, confirming that the deferred imitation exhibited by Group Paired/B 2-Day was not attributable to chance. These results reveal that looking at the paired puppets for a total of only $11 \mathrm{~min}$ or less over 2 days was sufficient for the infants to form an association between them and remember it for 2 more days, at which time that association mediated the transfer of imitation from Puppet A to Puppet $B$ during the deferred test. In addition, these results eliminate the possibility that Group Unpaired/B had failed to exhibit deferred imitation in Experiment $1 \mathrm{~A}$ because its total preexposure time to each puppet $(30 \mathrm{~min}$ ) was only half as long as the total preexposure time to the paired puppets $(1 \mathrm{~h})$.

\section{EXPERIMENT 2 Reactivating the Associated Memory}

In Experiment 2, we asked whether the association that was formed between Puppets A and B during the preexposure phase in Experiment $1 \mathrm{~A}$ was relatively enduring and, if so, whether it would continue to be specific to the original puppets. The latter question was of particular interest because generalization gradients are known to flatten as the retention interval increases for both animals (Riccio, Ackil, \& Burch-Vernon, 1992; Thomas \& Lopez, 1962) and human infants (Borovsky $\&$ Rovee-Collier, 1990). To answer these questions required assessing the transfer of imitation after a substantially longer delay. Because 6-month-olds' memory of the puppet imitation task is forgotten after only 1 day (the retention interval in Experiments 1A and 1B), however, it was first necessary to reactivate the memory.

Reactivation, also called perceptual priming (Cave, 1997; Rovee-Collier, 1997), is an automatic process that alleviates forgetting when an individual is briefly exposed to an isolated component of the original event (a prime) after forgetting has occurred but prior to the longterm retention test. Originally described in studies with infant rats (Spear, 1973; Spear \& Parsons, 1976), reactivation procedures have been used successfully with a variety of species and ages to recover forgotten memories (Hildreth \& Rovee-Collier, 2002; Mactutus, Riccio, \& Ferek, 1979; Matzel, Collin, \& Alkon, 1992; Rovee-Collier, Sullivan, Enright, Lucas, \& Fagen, 1980; Sheffield \& Hudson, 1994; Tulving \& Schacter, 1990). Although the characteristics of reactivated and newly acquired memories differ in a number of respects (Mactutus et al., 1979), there is evidence that forgetting continues even after the newly acquired memory becomes inaccessible (Morgan, Flint, \& Riccio, 1998). Nonetheless, a number of researchers have found that reactivation preserves memory specificity over relatively long delays (Bouton,
Nelson, \& Rosas, 1999; Riccio et al., 1992; Riccio, Richardson, \& Ebner, 1984, 1999; Rovee-Collier, Patterson, \& Hayne, 1985; Shields \& Rovee-Collier, 1992).

Because Boller (1997) had found no evidence of SPC at 6 months of age 1 day after reactivation (3 weeks after training), we were unsure whether an association formed during the preexposure phase could be reactivated at all, much less after a 3-week delay. Boller, however, had preexposed infants to two paired contexts, trained and primed infants in the presence of one context, and tested them in the presence of the other. Since then, we have found that infants treat the context differently at 6 months of age than at any other age during the 1st postnatal year (Hartshorn et al., 1998). Even if the association between the two puppets could be reactivated 3 weeks later, however, 6-month-olds' short-lived memory of the puppet imitation task might not be reactivated after this delay (Barr et al., 2002). Should infants not respond to Puppet B during the 3-week deferred imitation test in Experiment 2, we would not know whether their failure occurred because their memory of the original association between the paired puppets was not reactivated or because their memory of the puppet imitation task was not reactivated.

To eliminate the latter possibility and ensure that the memory of the puppet imitation task would be successfully reactivated, therefore, we included an intermediate step in Experiment 2-namely, associating the puppet imitation task with an operant train task. The puppettrain association is formed if the target actions are modeled on Puppet A in the presence of the train. Six-montholds typically remember the train task for 2 weeks, and after the puppet imitation task has been associated with it, they remember the puppet imitation task for 2 weeks too (Barr et al., 2001). Furthermore, when the memory of the train task is reactivated 1 week after infants have forgotten it ( 3 weeks after training), the associated memory of the puppet imitation task is reactivated as well (Barr et al., 2002). ${ }^{2}$

For the memory of the puppet imitation task to be retrieved at the time of testing, however, the train memory must be retrieved first. If infants are tested with the puppet first, they do not imitate the modeled actions (Barr et al., 2001). In other words, the memory of the train task "carries" the memory of the puppet imitation task along with it. By taking this intermediate step in Experiment 2, we were assured that if infants did not transfer imitation from Puppet A to Puppet B after reactivation, they would have failed to remember the association between the two puppets rather than the modeled actions.

\section{Method}

Subjects. The sample consisted of 18 full-term and healthy 6month-old infants ( 6 girls, 18 boys), recruited as before. They were Asian $(n=1)$ and Caucasian $(n=17)$, and their mean age on the first day of the experiment was 191.0 days $(S D=9.4)$. Their parents' mean educational attainment was 15.6 years $(S D=1.0)$, and their mean rank of socioeconomic status (Nakao \& Treas, 1992) was $67.7(S D=24.3)$. Additional infants were excluded from the final 
Table 3

Regimen of Stimuli Presented over 21 Days During Five Experimental Phases as a Function of Group (Experiment 2)

\begin{tabular}{lccccc}
\hline \multicolumn{1}{c}{ Group } & $\begin{array}{c}\text { Preexposure } \\
\text { (Days 1-7) }\end{array}$ & $\begin{array}{c}\text { Operant Training } \\
\text { (Days 8-9) }\end{array}$ & $\begin{array}{c}\text { Modeling } \\
(\text { Day 9) }\end{array}$ & $\begin{array}{c}\text { Reactivation } \\
\text { (Day 20) }\end{array}$ & $\begin{array}{c}\text { Test } \\
\text { (Day 21) }\end{array}$ \\
\hline Paired/B-train & $\mathrm{A}+\mathrm{B}$ & train & train+A & $\mathrm{A}$ & $\mathrm{B}$ \\
Paired[train]/B-train & $\mathrm{A}+\mathrm{B}$ & train & train+A & train & $\mathrm{B}$ \\
Paired/B-no train & $\mathrm{A}+\mathrm{B}$ & none & $\mathrm{A}$ & $\mathrm{A}$ & $\mathrm{B}$ \\
\hline
\end{tabular}

Note- $A$ and $B$ refer to different puppets.

sample for failing to meet the original learning criterion $(n=4)$, crying for 2 consecutive minutes in any of the four sessions $(n=2)$, illness $(n=1)$, or equipment failure $(n=1)$

As they became available for study, the infants were randomly assigned to one of two groups: Group Paired/B-Train and Group Paired/B-No Train (see Table 3). A third group, Group Paired[Train]/ B-Train, was added later, after the completion of the experiment. In the group labels, the letter after the slash indicates the test puppet, and "train" or "no train" indicates whether the target actions were modeled in the presence of the train or not, respectively.

Apparatus. The operant apparatus consisted of an HO-scale (miniature) train in a wooden-framed box $(58 \times 58 \times 35 \mathrm{~cm})$, three sides of which were enclosed by a colorful patterned curtain. The front of the box was Plexiglas $(58 \times 35 \mathrm{~cm})$, and a Plexiglas lever $(30 \times$ $12.5 \mathrm{~cm}$ ) was mounted at its base. When depressed, the lever operated a microswitch that was connected to an interface box and an IBM Thinkpad-350 laptop computer. A Quick Basic computer program timed the experimental phases, delivered the reinforcer, and registered all microswitch operations in 10-sec bins.

Two train sets, counterbalanced within and across groups, were used. One set was green and had a green curtain with yellow squares. Its train engine was black, and its rail cars were brown, silver, and purple. The other set was pink and had a red-and-bluestriped curtain. Its train engine was black, and its rail cars were brown, green, and red. In both sets, numerous small toys were placed about the track, and a 40-W white light bulb in the upper right corner continuously illuminated the interior of the train box during experimental phases. At the outset of each session, the designated train was positioned immediately behind the front window on a circular track (47.5-cm diameter).

The puppets were the same as those in Experiment 1A (see Figure 1).

Procedure. The preexposure phase was the same that as for the paired groups in Experiment 1A. All the groups were simultaneously preexposed to Puppets A and B (the cow and the duck; designation was counterbalanced within groups) for a total of $1 \mathrm{~h}$ each day on 7 consecutive days. Because the unpaired control group had not formed an association during the preexposure phase in Experiment 1A (see also Coppock, 1958; Seidel, 1959), an unpaired group was not included in Experiment 2.

Operant training. On Days 8 and 9, Group Paired/B-Train and Group Paired[Train]/B-Train were trained in the operant task. At this time, the train set was placed on a table in the infant's home, and the infant sat on the caregiver's lap in front of it with the lever chesthigh. The infants received an identical 8-min training session on 2 consecutive days. Sessions began with a 1-min nonreinforcement period during which the lever was deactivated. In Session 1, this was the baseline phase, during which the infants' unlearned rate of leverpressing was recorded. Next followed a 6-min reinforcement period (acquisition), during which the lever was active, and each leverpress moved the train for $2 \mathrm{sec}$ (see Figure 4). Leverpresses that occurred while the train was in motion were registered by the computer but had no effect on delivery of the reinforcer. Sessions ended with a 1-min nonreinforcement phase, during which the lever was again deactivated so that leverpresses did not move the train. In Session 2, this phase served as the immediate retention test, during which infants' final level of learning was measured. To be eligible for retention testing, an infant was required to meet a standard learning criterion by responding at least 1.5 times above his or her baseline rate in 2 of any 3 consecutive minutes of acquisition.

Modeling phase. Immediately after the final training session (Day 9), the caregiver turned her chair to the side so that the train remained in sight to the infant's left or right, and then the experimenter modeled the target actions on Puppet A (see Figure 5). This demonstration was the same as in Experiments 1A and 1B. The infants in Group Paired/B-No Train saw the puppet demonstration on Day 8 but did not learn the train task. This group was included in order to determine whether the train task was a prerequisite for reactivation of the infants' memory of the Puppet A-Puppet B association 3 weeks later. As in Experiment 1A, the infants in all the groups repeated the target actions three times immediately after the demonstration. The duration of the immediate imitation phase was approximately $4 \mathrm{~min}(M=238 \mathrm{sec}, S E=33)$ and did not differ across groups. The infants scored 1.83, on average, in each group.

Reactivation treatment. The infants in all the groups received a reactivation treatment with Puppet A 20 days after the original modeling session. For Group Paired/B-Train (the SPC group in Experiments $1 \mathrm{~A}$ and $1 \mathrm{~B}$ ) and Group Paired/B-No Train, the reactivation treatment consisted of demonstrating the target actions on Puppet A three times for a total of $30 \mathrm{sec}$. We have repeatedly documented that 6-month-olds cannot imitate the target actions 1 day later if they see them modeled for only $30 \mathrm{sec}$ (Barr et al., 1996; Barr et al., 2002). For the infants in Group Paired/B-Train, who previously saw the target actions modeled in the presence of the train, the train was again present during the reactivation treatment (see Figure 5). For the infants in Group Paired/B-No Train, the train was not present during the reactivation treatment.

For Group Paired[Train]/B-Train, the reactivation treatment was a 2-min exposure to the moving train while the response lever was deactivated. These infants were never exposed to Puppet A again. The frequency and temporal pattern of train movement were computer programmed to reproduce each infant's responding during the final 2 min of acquisition in Session 2. After the 2 min timed out, the caregiver removed the infant, and the reactivation treatment was over.

Long-term retention test. We previously found that retrieval of the train memory was necessary in order for the memory of the puppet imitation task to be retrieved. In the present experiment, therefore, we initially tested the infants' memory of the train task, to ensure that it had been retrieved, before we tested their memory of the puppet imitation task (i.e., the order of testing was not counterbalanced).

The long-term retention tests with the train and Puppet B occurred 1 day after the reactivation treatment, 3 weeks after the target actions were originally modeled. Group Paired/B-Train and Group Paired[Train]/B-Train received a 2-min retention test with the train. During the test, the response lever was deactivated so that leverpresses did not move the train. After the long-term retention test, the lever was activated during a 6-min motivational control phase, during which leverpresses again moved the train. This phase was introduced to ensure that the infants who had performed poorly during the train test were not ill, fatigued, or otherwise unmotivated on that particular day. None was; all the infants responded appropriately to the contingency. 


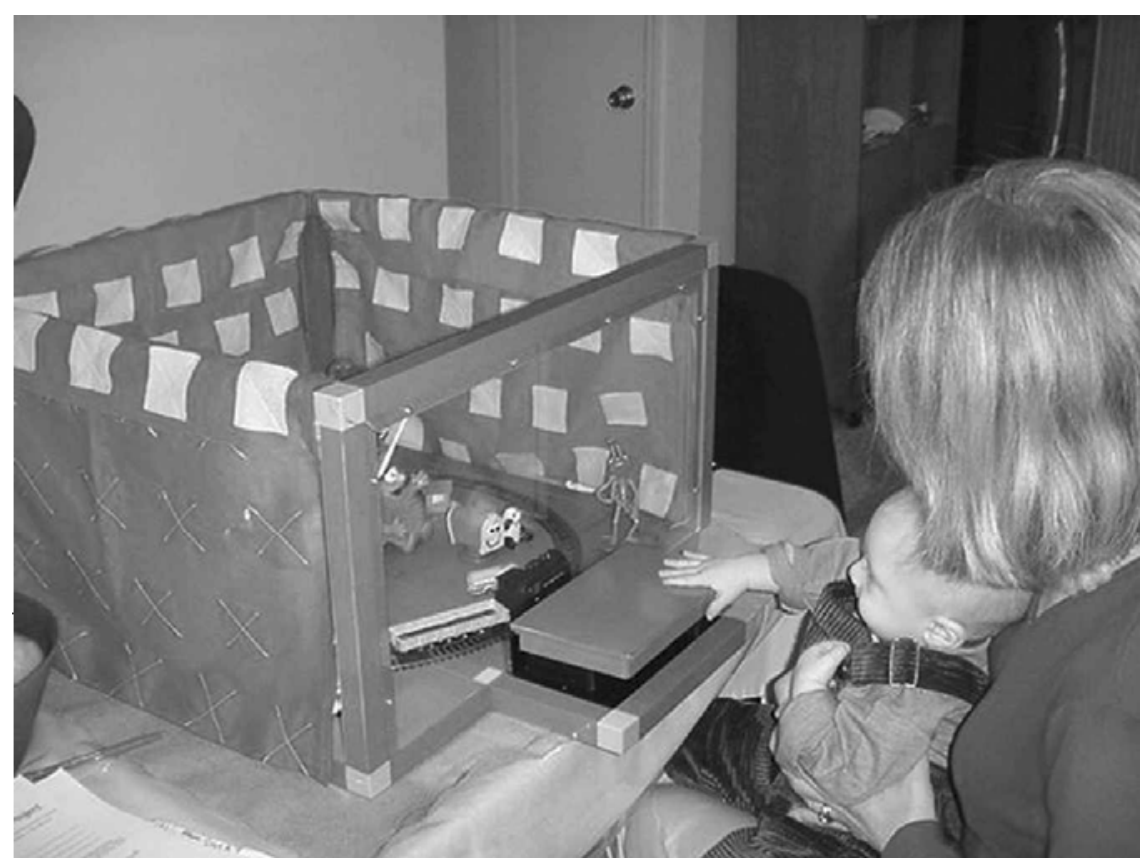

Figure 4. A 6-month-old pressing the lever to move the toy train. Each response during a reinforcement phase moved the train for 2 sec.

After the train test, the caregiver again rotated her chair to the side, and the infants in Group Paired/B-Train and Group Paired[Train]/ B-Train were tested for transfer of imitation with Puppet B. Group Paired/B-No Train was tested only with Puppet B. It did not receive an initial train test.

\section{Results and Discussion}

Operant test. To ensure that the infants had indeed retrieved the memory of the train task before they were tested for retention of the puppet task, we assessed the infants' retention by using an individual measure of relative response, the baseline ratio, which our laboratory had used in all previous operant studies of infant memory (Rovee-Collier, 1996). This measure was calculated by dividing each infant's response rate during the longterm retention test by that same infant's response rate during the baseline phase. A mean baseline ratio of 1.00 indicated that a group had responded at its baseline level during the long-term retention test (i.e., no retention). A mean baseline ratio significantly greater than 1.00 indicated that a group had exhibited significant retention.

As was expected, the infants in Group Paired/B-Train and Group Paired[Train]/B-Train exhibited significant retention of the train task 1 day after reactivation $[t(5)=3.72$, $p<.01$, and $t(5)=3.23, p<.05$, respectively], confirming that the train memory had indeed been retrieved. Thus, exposure to the train had directly reactivated the train memory of Group Paired[Train]/B-Train, and exposure to Puppet A had indirectly reactivated the train memory of Group Paired/B-Train. The latter data confirmed that the infants had associated Puppet A with the train 3 weeks earlier (see Figure 6), replicating the finding of Barr et al. (2002).
Imitation test. The videotaped imitation sessions were scored as before by two trained observers, one of which was naive with respect to the infants' group assignment. Both observers scored $94 \%$ of the videotapes for the immediate and the deferred imitation tests; their interobserver reliability was $98 \%(\mathrm{kappa}=.95)$. When the two raters differed, the primary rater's score was assigned. In Experiment 2, the raters disagreed on one occasion regarding the presence or absence of one of the three behaviors.

A one-way ANOVA over the mean imitation scores during the immediate imitation test that followed modeling of the target actions indicated that Group Paired/ B-Train, Group Paired[Train]/B-Train, and Group Paired/ B-No Train did not differ $[F(2,15)<1]$. All the infants imitated, and all means equaled 1.83. This result eliminated group differences in initial learning as a potential account for any group differences in deferred imitation.

The mean deferred imitation test scores during the longterm retention test for Group Paired/B-Train, Group Paired[Train]/B-Train, and Group Paired/B-No Train are shown in Figure 7. A one-way ANOVA over the mean deferred imitation test scores of the three groups from Experiment 2 plus Group Unpaired/B from Experiment 1A (a cross-experiment analysis) indicated that they differed significantly $[F(3,20)=5.23, p<.01]$. A post hoc test (Duncan's multiple range test, $p<.05)$ revealed that the mean deferred imitation test scores of Group Paired/B-Train and Group Paired[Train]/B-Train did not differ, and both significantly exceeded the mean deferred imitation test scores of Group Paired/B-No Train and Group Unpaired/B, which also did not differ (see Figure 7). 


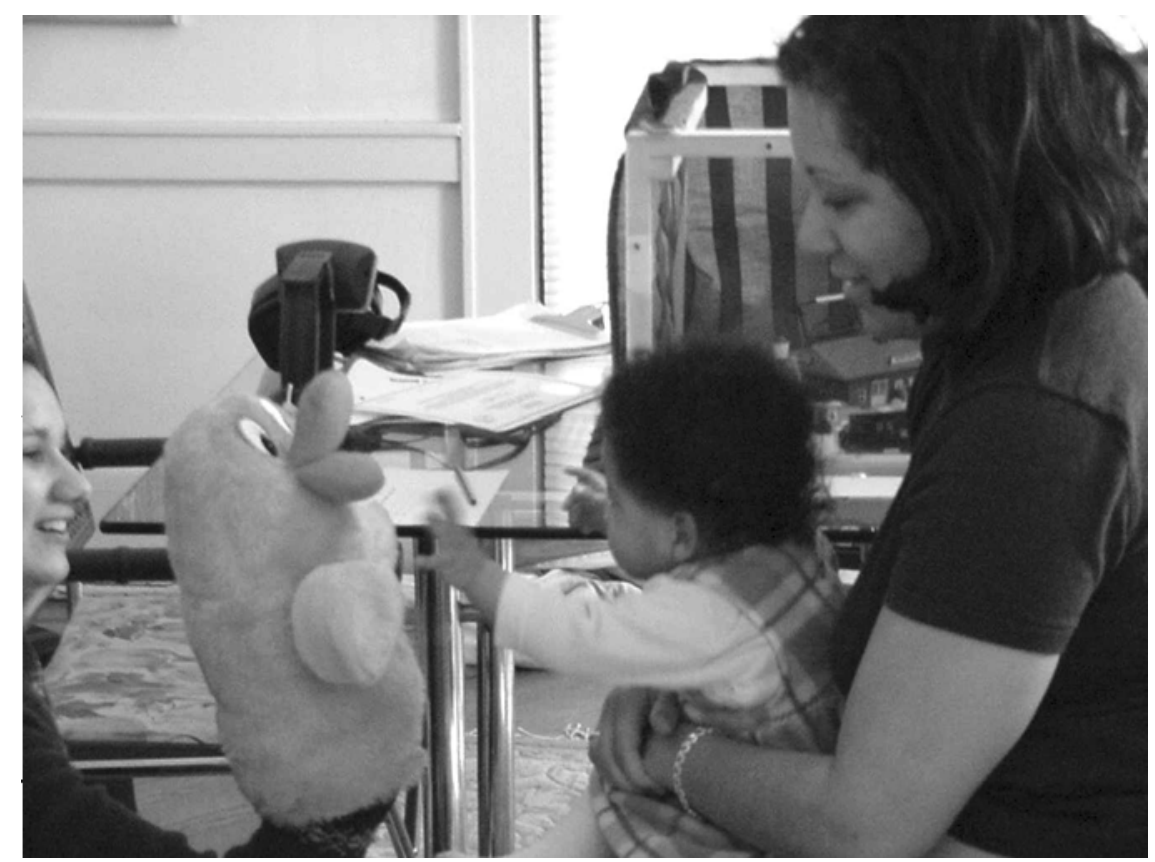

Figure 5. The experimental arrangement in Experiment 2. Shown here is a 6-month-old being tested with the duck, with the train set in the background. The target actions were previously modeled on Puppet A immediately after operant training in Session 2 while the train set was in the infant's view. Reactivation and testing of all operantly trained groups occurred in this context.

The finding that Puppet A reactivated the memory of Puppet B for the infants in Group Paired/B-Train provided additional evidence that an association had been formed between Puppets A and B during the initial preexposure phase. In fact, the infants had not seen Puppet B prior to the deferred imitation test, since it had been paired with Puppet A during the preexposure phase more than 3 weeks earlier. Had Puppet A not reactivated the infants' memory of Puppet B, the infants would not have recognized Puppet B and would not have imitated the target actions on it during the deferred imitation test.

Procedurally, the only difference between Group Paired/ B-Train and Group Paired[Train]/B-Train was whether Puppet A or the train, respectively, was the reactivation

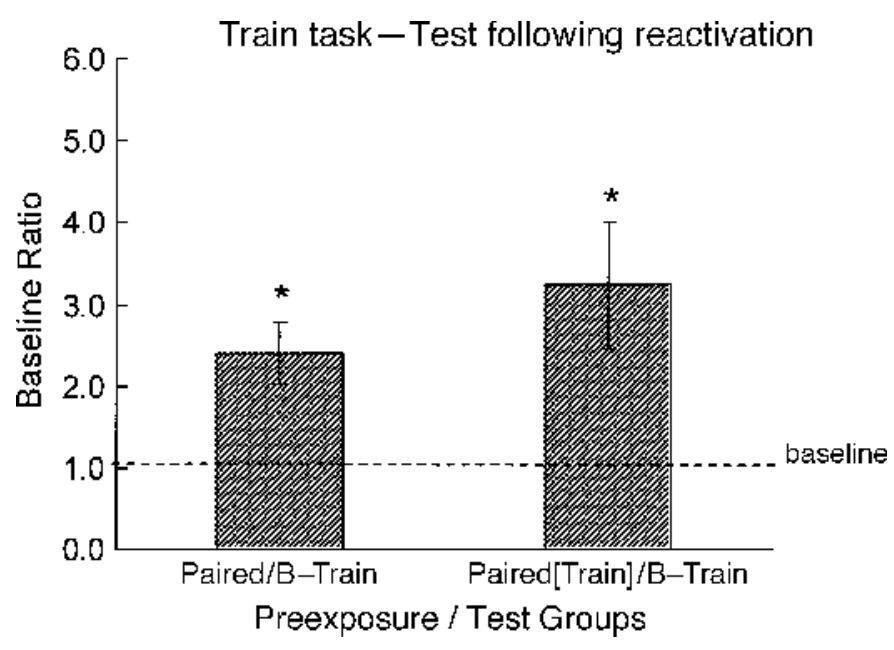

Figure 6. The mean baseline ratios $(+1 S E)$ of 6-month-olds in Groups Paired/B-Train and Paired[Train]/B-Train (Experiment 2). The dotted line indicates baseline. An asterisk indicates that a group exhibited significant retention (i.e., $M$ baseline ratio significantly $>1.00$ ). 


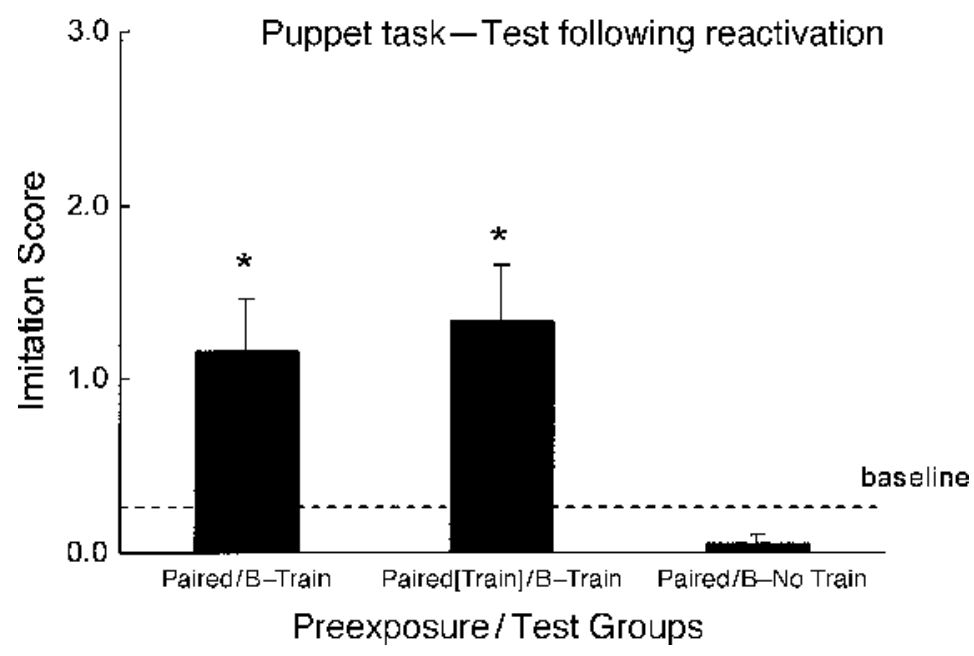

Figure 7. The mean deferred imitation test scores $(+1 S E)$ of 6-month-olds in Groups Paired/B-Train, Paired[Train]/B-Train, and Paired/B-No Train (Experiment 2). An asterisk indicates that a group scored significantly higher than Group Paired/B-No Train.

stimulus. The fact that both groups exhibited significant imitation on Puppet B reveals that, for both groups, the original association between Puppet A and Puppet B must have been reactivated, but how this occurred in each case may have been different. For Group Paired[Train]/ B-Train, we think that the train directly reactivated the memory of the train task and indirectly reactivated the memory of the Puppet A-Puppet B association by virtue of the association between the train and Puppet A (recall that the target actions were modeled on Puppet A in the presence of the train). This result is consistent with the finding in Barr et al. (2002) that the train indirectly primed the memory of the puppet imitation task by virtue of its association with Puppet A. For Group Paired/B-Train, however, an additional step may have been necessary. We think that Puppet A first directly reactivated the associated memory of the train, which then reactivated the memory of the train task. When the memory of the train task was reactivated, the memory of the association between Puppet A and Puppet B was reactivated as well. The fact that Puppet $A$ failed to directly reactivate the memory of its association with Puppet B in the absence of an association with the train (Group Paired/B-No Train) reveals that the train task mediated reactivation of the Puppet A-Puppet B memory-a result also consistent with that of Barr et al. (2002).

Alternatively, the memory of Puppet B could have been activated by virtue of its initial association with Puppet $\mathrm{A}$ at the time at which the target actions had been modeled on Puppet A in the presence of the train in Phase 2. If this were the case, any new memory that included Puppet A would have included the memory of Puppet B as well. By this account, either Puppet A or the train, when used as the reactivation stimulus, would have directly reactivated the memory of Puppet B. In other words, an associatively activated representation would have been reactivated (for discussions, see Dwyer, Macintosh, \& Boakes, 1998; Ward-Robinson \& Hall, 1996, 1998).

Whatever the account, the target association hypothesis attributes priming (reactivation) effects to the temporary strengthening of either a direct connection between the target and the prime or the connections between stimuli to which the target (here, Puppet B) and the prime (here, the train or Puppet A) are both linked (i.e., shared associates). This hypothesis is based on the encoding specificity principle (Tulving \& Thomson, 1973). According to Nelson and colleagues (Nelson, Bennett, \& Leibert, 1997; Nelson \& Goodman, 2002), shared associates facilitate priming and increase the probability of retrieval because they provide another (albeit indirect) means of linking the prime to the target.

Finally, the data in Experiment 2 attest to the durability of associations. The association between Puppet A and Puppet B that had been formed during the initial SPC phase was relatively enduring. The association still mediated the transfer of infants' learned responding from one member of the original association to the other during an imitation test almost 3.5 weeks after it was formed.

\section{GENERAL DISCUSSION}

Talk, Gandhi, and Matzel (in press) investigated the brain structures that are necessary and sufficient for SPC. Adult rats were randomly assigned to one of three conditions: intact, sham operated, or hippocampally lesioned. Half of the rats in each condition were preexposed to a tone and white noise that were presented sequentially (paired group), and the other half were preexposed to a tone and white noise that were separated by $4 \mathrm{~min}$ (unpaired group). Twenty-four hours later, the tone was paired with shock for all the animals. Later, the rats were 
tested with the white noise in a lick-suppression paradigm. The rats in the paired group exhibited SPC and suppressed drinking to the white noise, but the rats in the unpaired group did not. In addition, hippocampally lesioned animals had significantly impaired SPC test performance, as compared with sham-operated and intact animals.

To examine the role of the hippocampus in SPC further, Talk et al. (in press) used EEG recordings to assess hippocampal response during different SPC phases. During the initial preexposure phase, the sensory-evoked hippocampal response of the paired and the unpaired groups of intact animals did not differ. During Phase 2, however, the evoked response from the hippocampus increased when the tone was followed by shock in the paired group, but not in the unpaired group. The authors suggested that the hippocampal response may be preparatory to the behavioral response when one of the originally paired stimuli is subsequently associated with shock.

Although these results implicate the hippocampus in SPC in adult rats, the hippocampus is still relatively immature early in development. Yet Chen et al. (1991) have found that immature rat pups actually displayed enhanced performance on SPC tasks relative to older rat pups and adults when stimuli were initially presented simultaneously but that they were less successful when stimuli were presented sequentially and separated by long delays. Findings such as these led Spear, McKinzie, and Arnold (1994) to suggest that immature organisms may process information in a manner that is fundamentally different from older organisms. Whether similar developmental differences in processing occur for human infants, however, is unknown.

The present study documents that even very young infants pick up important information by merely observing their physical surround and learning the relationships between what they see. Moreover, they do so with amazing rapidity. These learned associations are also readily interconnected, thereby establishing an associative network that can be brought "on line" to facilitate both the retrieval and the transfer of prior learning. As a result, by the time infants are old enough to self-locomote, they are able to transfer the wealth of new learning that locomotion affords to the many stimuli that have been linked within this network, thereby dramatically expanding the early knowledge base. Given the large number of associations that very young infants must spontaneously acquire, those that we documented in the present study surely represent just the tip of the proverbial iceberg.

\section{REFERENCES}

Barr, R., Dowden, A., \& Hayne, H. (1996). Developmental changes in deferred imitation by 6- to 24 -month-old infants. Infant Behavior \& Development, 19, 159-170.

Barr, R, Vieira, A., \& Rovee-Collier, C. (2001). Mediated imitation at 6 months of age: Remembering by association. Journal of Experimental Child Psychology, 79, 229-252.

Barr, R, Vieira, A., \& Rovee-Collier, C. (2002). Bidirectional priming in infants. Memory \& Cognition, 30, 246-255.

BOLLER, K. (1997). Preexposure effects on infant learning and memory. Developmental Psychobiology, 31, 93-105.
Borovsky, D., \& Rovee-Collier, C. (1990). Contextual constraints on memory retrieval at 6 months. Child Development, 61, 1569-1583. Bouton, M. E., Nelson, J. B., \& Rosas, J. M. (1999). Stimulus generalization, context change, and forgetting. Psychological Bulletin, 125, 171-186.

BRogDEN, W. J. (1939). Sensory preconditioning. Journal of Experimental Psychology, 25, 323-332.

BRogden, W. J. (1947). Sensory preconditioning of human subjects. Journal of Experimental Psychology, 37, 527-539.

Cave, C. B. (1997). Very long-lasting priming in picture naming. Psychological Science, 8, 322-325.

Chen, W. J., Lariviere, N. A., Heyser, C. J., Spear, L. P., \& Spear, N. E. (1991). Age-related differences in sensory conditioning in rats. Developmental Psychobiology, 24, 307-326.

Cheslock, S. J., High, J. M., Varlinskaya, E. L., \& Spear, N. E. (2000, November). Perceptual configuration in newborn rats: Sensory preconditioning and second order conditioning. Paper presented at the meeting of the International Society for Developmental Psychobiology, New Orleans.

Cohen, L. B. (1976). Habituation of infant visual attention. In T. J. Tighe \& R. N. Leaton (Eds.), Habituation: Perspectives from child development, animal behavior, and neurophysiology (pp. 207-238). Hillsdale, NJ: Erlbaum.

Coppock, W. J. (1958). Pre-extinction in sensory preconditioning.Journal of Experimental Psychology, 47, 355-357.

DeCAsper, A. J., \& Spence, M. J. (1986). Prenatal maternal speech influences newborns' perception of speech sounds. Infant Behavior \& Development, 9, 133-150.

Dwyer, D. M., Macintosh, N. J., \& Boakes, R. A. (1998). Simultaneous activation of the representations of absent cues results in the formation of an excitatory association between them. Journal of Experimental Psychology: Animal Behavior Processes, 24, 163-171.

Hartshorn, K., Rovee-Collier, C., Gerhardstein, P., Bhatt, R. S., Klein, P. J., Aaron, F., Wondoloski, T. L., \& Wurtzel, N. (1998). Developmental changes in the specificity of memory over the first year of life. Developmental Psychobiology, 33, 61-78.

Hayne, H., Boniface, J., \& BarR, R. (2000). The development of declarative memory in human infants: Age-related changes in deferred imitation. Behavioral Neuroscience, 114, 77-83.

Hayne, H., Greco, C., Earley, L. A., Griesler, P. C., \& RoveeCOLLIER, C. (1986). Ontogeny of early event memory: II. Encoding and retrieval by 2 - and 3-month-olds Infant Behavior \& Development, 9, 461-472.

Hildreth, K., \& Rovee-Collier, C. (2002). Forgetting functions of reactivated memories over the first year of life. Developmental Psychobiology, 40, 277-288.

Mactutus, C. F., Riccio, D. C., \& Ferek, J. M. (1979). Retrograde amnesia for old (reactivated) memory: Some anomalous characteristics. Science, 204, 1319-1320.

Matzel, L. D., Collin, C., \& Alkon, D. L. (1992). Biophysical and behavioral correlates of memory storage: Degradation and reactivation. Behavioral Neuroscience, 106, 954-963.

Morgan, R. E., Flint, R. W., JR., \& Riccio, D. C. (1998). Timedependent changes in inaccessible memory. Psychonomic Bulletin \& Review, 5, 523-527.

NAKaO, K., \& Treas, J. (1992). The 1989 socioeconomic index of occupations: Construction from the 1989 occupational prestige scores (General Social Survey Methodological Reports No. 74). Chicago: NORC.

Nelson, D. L., Bennett, D. J., \& Leibert, T. W. (1997). One step is not enough: Making better use of association norms to predict cued recall. Memory \& Cognition, 25, 785-796.

Nelson, D. L., \& Goodman, L. B. (2002). Experiencing a word can prime its accessibility and its associative connections to related words. Memory \& Cognition, 30, 380-398.

Riccio, D. C., Ackil, J. A., \& Burch-Vernon, A. (1992). Forgetting of stimulus attributes: Methodological implications for assessing associative phenomena. Psychological Bulletin, 112, 433-445.

Riccio, D. C., Richardson, R., \& Ebner, D. L. (1984). Memory retrieval deficits based upon altered contextual cues: A paradox. Psychological Bulletin, 96, 152-165.

Riccio, D. C., Richardson, R., \& Ebner, D. L. (1999). The contextual 
change paradox is still unresolved: Comment on Bouton, Nelson, \& Rosas (1999). Psychological Bulletin, 125, 187-189.

Rovee-Collier, C. (1996). Measuring infant memory: A critical commentary. Developmental Review, 16, 301-310.

Rovee-Collier, C. (1997). Dissociations in infant memory: Rethinking the development of implicit and explicit memory. Psychological Review, 104, 467-498.

Rovee-Collier, C., Patterson, J., \& Hayne, H. (1985). Specificity in the reactivation of infant memory. Developmental Psychobiology, 18, 559-574.

Rovee-Collier, C., Sullivan, M. W., Enright, M. K., Lucas, D., \& FAGEN, J. W. (1980). Reactivation of infant memory. Science, 208, $1159-1161$.

SEIdEL, R. J. (1959). A review of sensory preconditioning. Psychological Bulletin, 46, 58-73.

Sheffield, E. G., \& Hudson, J. A. (1994). Reactivation of toddlers' event memory. Memory, 2, 447-465.

Shields, P. J., \& Rovee-Collier, C. (1992). Long-term memory for context-specific category information at 6 months. Child Development, 63, 245-259.

Silver, C. A. \& Meyer, D. R. (1954). Temporal factors in sensory preconditioning. Journal of Comparative \& Physiological Psychology, 47, 57-59.

Spear, N. E. (1973). Retrieval of memories in animals. Psychological Review, 80, 163-194.

Spear, N. E., McKinzie, D. L., \& Arnold, H. M. (1994). Suggestions from the infant rat about brain dysfunction and memory. In J. Delacour (Ed.), The memory system of the brain (pp. 278-315). Singapore: World Scientific.

SpeAr, N. E., \& Parsons, P. J. (1976). Analysis of a reactivation treatment: Ontogenetic determinants of alleviated forgetting. In D. L. Medin, W. A. Roberts, \& R. T. Davis (Eds.), Processes of animal memory (pp. 135-165). Hillsdale, NJ: Erlbaum.

Talk, A. C., Gandhi, C. C., \& MATZel, L. D. (in press). Hippocampus function during behaviorally-silent associative learning: A dissociation of memory storage and expression. Learning \& Memory.

Thomas, D. R., \& Lopez, L. J. (1962). The effect of delayed testing on generalization slopes. Journal of Comparative \& Physiological Psychology, 64, 77-80.
Thомpson, R. J. (1972). Sensory preconditioning. In R. J. Thompson \& J. F. Voss (Eds.), Topics in learning and performance (pp. 105-129). New York: Academic Press.

Tulving, E., \& Schacter, D. L. (1990). Priming and human memory systems. Science, 247, 301-306.

Tulving, E. \& Thomson, D. M. (1973). Encoding specificity and retrieval processes in episodic memory. Psychological Review, 80, 352373.

WARd-Robinson, J., \& HALL, G. (1996). Backward sensory preconditioning. Journal of Experimental Psychology: Animal Behavior Processes, 22, 395-404.

WARD-RoBINSON, J., \& HALL, G. (1998). Backward sensory preconditioning when reinforcement is delayed. Quarterly Journal of Experimental Psychology, 51B, 349-362.

\section{NOTES}

1. The data for Experiment 1B were collected after Experiment 1A had been completed.

2. Barr et al. (2002) also tested a forgetting control group that was trained in both the puppet imitation and operant tasks but received no reactivation treatment, a reactivation control group that received a reactivation treatment with the train but was not trained on either task, and a puppet-only control group that learned the puppet imitation task but not the train task and received a reactivation treatment with the puppet. None exhibited retention during the long-term test. Data from the forgetting control group confirmed that the train and the puppet tasks were forgotten 3 weeks after training without a reactivation treatment. Data from the reactivation control group confirmed that the infants did not produce the target actions on the puppet or respond to the train unless they had been previously trained. Data from the puppet-only control group confirmed that the infants who originally saw the puppet demonstration but did not learn the train task could not remember the imitation task 3 weeks later, even if they received a reactivation treatment with the puppet.

(Manuscript received November 4, 2002; revision accepted for publication January 24, 2003.) 